\title{
The Role of Unemployment in the Run of Life Chances in Hungary
}

\author{
Annamária Uzzoli \\ Hungarian Academy of Sciences, Centre of Regional Studies, Central and North Hungarian Research Institute, H-7621 Pécs, \\ Papnövelde u. 22, Hungary \\ Correspondence should be addressed to Annamária Uzzoli, annamaria.uzzoli@gmail.com
}

Received 9 September 2010; Revised 25 October 2010; Accepted 12 November 2010

Academic Editor: Peter Congdon

Copyright (c) 2011 Annamária Uzzoli. This is an open access article distributed under the Creative Commons Attribution License, which permits unrestricted use, distribution, and reproduction in any medium, provided the original work is properly cited.

This paper studies the connection between health—especially life expectancy-and unemployment in Hungary. Unemployment and health are recognised as being linked, though the relationship is complex. Unemployment happens to many people mainly in the period of crisis and can be a stressful and depressing time of life. On the one hand, the general state of health of the Hungarian people is worse than justified by the level of economic development. On the other hand, the role of the present economic crisis is to be predicted in the future run of health condition. Moreover, it would probably result health deterioration for those social groups who are most affected by unemployment and poverty. The study consists of two major structural parts. The theoretical part provides an insight to the specific literature, while the empirical chapter examines the link between socioeconomic indicators, unemployment, and life chances with correlation and regression calculations.

\section{Introduction}

Health, social welfare, and economy are notions that are tightly interconnected and complement each other, therefore, health conditions of the human resources have an essential role in economic and social processes. Low educational qualification, unfavourable labour market position, low income, and unemployment go together with deteriorating living conditions, consequently it results in risking people's health. The effects of the credit crunch in the fall of 2008 and those of the fully evolved economic crisis in 2009 were most apparent in financial, economic, and labour market mechanisms. Due to the economic crisis, the shortfalls in investments and industrial production caused the rise of unemployment, mostly affecting poor and vulnerable social groups. Most of the European countries should be prepared for the treatment of the direct and indirect social, health, and health care consequences of the crisis. Particularly Central and Eastern European countries face serious challenges, where already existing healthcare conflicts would reappear and health inequalities would become more acute.

The bad health conditions of the region's population and its shorter life expectancy compared to the WesternEuropean average, crisis factors of health care inherited from socialism, and inadequate financing together mean a problem for health politics, which could not find an efficient solution even 20 years after the transition. Therefore, the role of the present economic crisis is to be predicted in the future run of health condition. On the one hand, it would probably result in health deterioration for the social groups who are most affected by unemployment and poverty. On the other hand, decreasing income and low-key consumption would result in limited possibilities for health conscious lifestyle. Thirdly, health might be considered as an asset to keep its position on the labour market, but in prevention and health protection large social differences will appear.

\section{Methods and Data}

The most important aim of the paper is to interpret the correlation of the change of labour market position and state of health. This paper intends to analyse the supposed relation between unemployment and run of life chances with the help of statistical indicators and bibliographical references.

The analysis is based on the approach to define the social determinants of health. Social determinants of health are the economic and social conditions under which people live which determine their health. These circumstances are shaped by the distribution of money, power, and resources 
at global, national, and local levels. The factors of the social-economic environment are firstly responsible for the development of life circumstances and social situation. One of the social determinants of health is unemployment. Social determinants of health including employment/unemployment have been recognized by researchers and World Health Organization. According to the so called Health Field Concept of the Lalonde model, environmental factors that determine the state of health are qualification, employment, and unemployment. This model was one of those models which has proven that the population's state of health is mostly neither determined by the quality of health care, nor by the development of the health care system, but by the effect of the environment and lifestyle [1].

The social determinants of health are mostly responsible for health inequalities - the unfair and avoidable differences in health status seen within and between countries. Responding to increasing concern about these persisting and widening inequities, WHO established the Commission on Social Determinants of Health $(\mathrm{CSDH})$ in 2005 to provide advice on how to reduce them. The definitive work on the social determinants is the 2008 report from WHO "Closing the Gap in a Generation: Health Equity through Action on the Social Determinants of Health" [2].

In the presentation of life expectancy changes, I took the index of average life expectancy at birth, which determines life chances in a complex way, since it is determined by death rates. Life expectancy means the average number of years to be lived, calculated from birth or from a particular age, so this is an average number of years that a newborn is expected to live if current mortality rates continue to apply [3]. The index reflects the overall mortality level of a population. It summarizes the mortality pattern that prevails across all age groups_children and adolescents, adults and the elderly [4]. Life expectancy is influenced by death rates, so they are even compound indexes for life chances. Economic circumstances also affect life expectancy. For example, life expectancy in the wealthiest areas is several years longer than in the poorest areas. This may reflect factors such as lifestyle as well as access to medical care.

Mortality rates depend on age distribution: if population ages, mortality rate increases. Comparing the mortality of the population's different age distributions is possible by calculating the life expectancy at birth, thus the mortality level of a population can be defined with one data. The better the mortality circumstances are, the higher the average life expectancy rates are at birth.

What tendencies have characterized life expectancies in Hungary during the last decades? How significant regional differences can be experienced regarding life expectancies in Hungary? Do regional differences unequivocally prove Western-Eastern splitting in health inequalities? How did the economic regime and the appearance of unemployment influence life chances after 1990? How strong is the connection between unemployment and life chances? Does the present crisis have an influence on life chances at all? Does favourable social-economic environment and low unemployment always mean better life chances?
To answer these questions, I used the regional analytical methods. In order to explain cause and effect correspondences I justified the link between socioeconomic indicators, unemployment, and life chances with correlation and regression calculations. I took the data from the publications and online database of the Hungarian Central Statistical Office and from databases of the European Union. In order to describe tendencies, I analyzed historical data, while to prove regional differences, I tried to obtain the most recent data from 2009. The level of examination of the statistical analysis is the county (NUTS level III).

The significance of the results of the enquiry lies in the regional characteristics of public health processes and socioeconomic factors determining health state. The aim was a multidisciplinary approach, using applied methodology and analysing configuration of life chances. In effect, to be aware of the population's health and illness correlation and its role in social-economic context is indispensable in regional development, social-economic planning, and political decision making. Similar regional analyses can be the starting point for a nationwide Health Impact Assessment.

\section{The Impact of Unemployment on Health Inequalities}

For the evaluation of risk factors and their prevention, it is of essential importance to analyse the social situation's role regarding health state and its effect on the health system.

Social inequalities related to health are present in every country and mostly depend on macroeconomic conditions. The interpretation of the social factors defining health inequalities (Figure 1) presumes that during a crisis, not only the labour market position and the level of income counts from a health point of view, but also the level and growth of already existing social and health inequalities.

The most important question is whether the social network protecting the poor and those liable to poverty is appropriate enough and whether the gap between the availability of health services is getting bigger. Health inequalities are always linked to economic inequalities, the unfairness of the distribution system, bad labour market positions, difficulties in the availability of health care and education, disadvantaged living and life conditions, and no chance of a healthy life [5].

Unemployment is the factor that has the strongest influence on health. The situation is the worst in case of middle aged males who become unemployed for the first time during a crisis period [6]. Indeed, unemployment makes you sick as it has a negative effect on the individual's identity, emotional world, and self-esteem. It increases the feeling of hopelessness, depressive symptoms, and the risk of suicide [7]. When crisis hits, everyone is about to keep one's workplace. Therefore, permanent uncertainty and increased stress result in physical and psychical diseases. Stress caused by unemployment results in the spread of riskful behaviour (medicine consumption, alcoholism, excessive smoking). The suicide rate of young or middle-age groups often correlates with the changes of unemployment rate. 


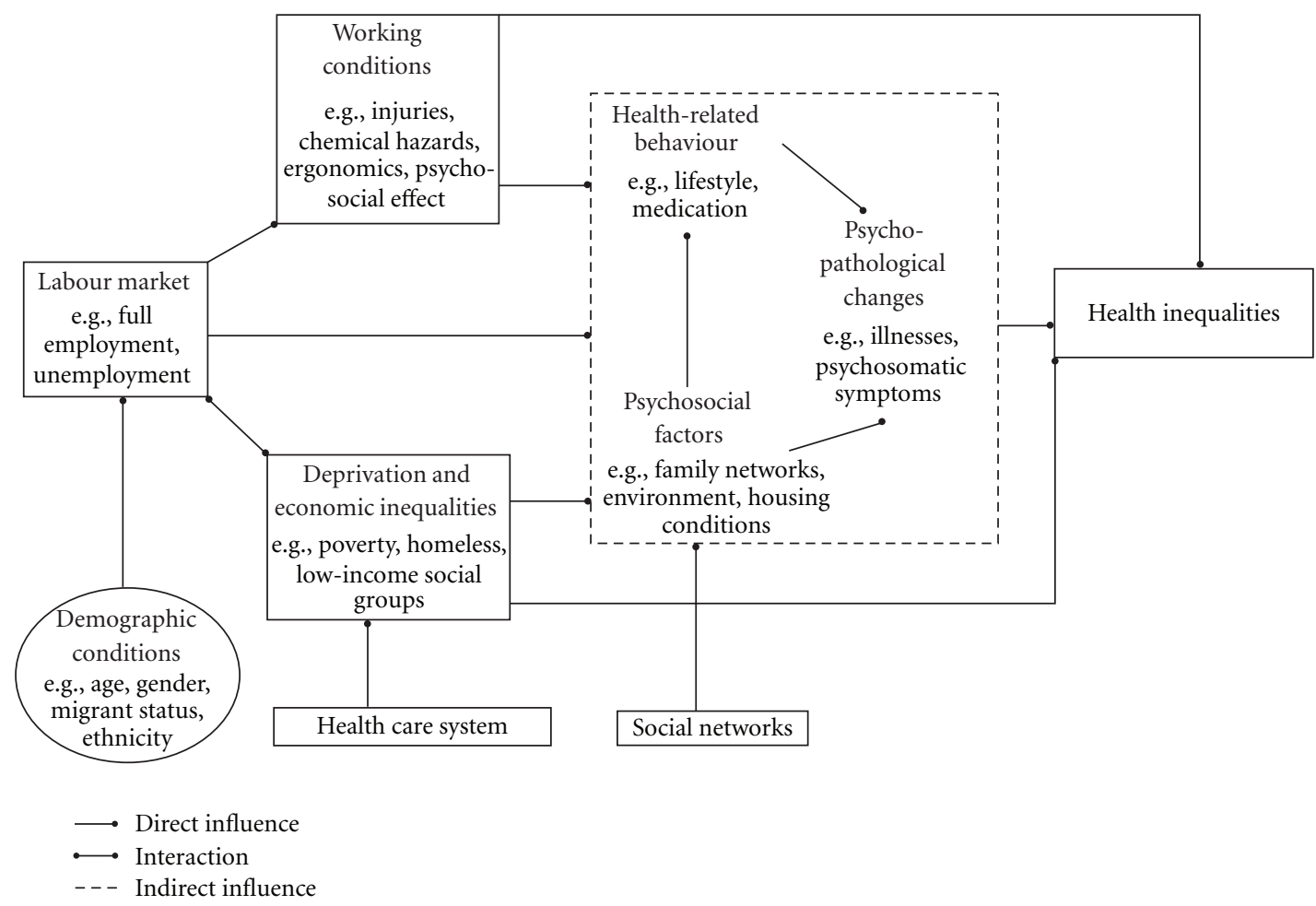

FIgURE 1: Theoretical frameworks of unemployment and health inequalities. Source: [5, Page 32] and own supplements.

"Unemployment does significantly affect suicide rates, but in a way that varies for income: In a positive manner for highincome countries, but in a negative manner for low-income countries" [8].

It was apparent during the 2009 economic crisis that beside growing unemployment, in some economic sectors the incomes decreased even for the employed due to for example necessity leave and a reduced working-time. The disadvantages of income drop were increased by the fact that families and households got indebted and their subsistence was in danger. As a consequence, the consumption, mainly the consumption of healthy products and the demand for health related services, decreased. One possible explanation is that in uncertain periods people tend to neglect their health thus health care and prevention does not reach the required level. Decreasing revenue makes it more difficult for the sick to reach the medical services [9].

The effect of the economic crisis on the health system can be seen on the availability of health services [10]. Unequal availability in geographical sense raises the question of regional inequalities, while in sociological sense it does so for the equality of chances. Unequal availability of health services is determined by the individual's sociocultural conditions [11]. To give access to medical services is one of the most effective ways to reduce poverty and social differences. Health system plays an important role in protecting labour force, therefore the resources for benefits should not be reduced in case of crisis. Consequently, investments in health and the health care system have an advantageous effect on social stability, thus on economy at the same time [12]. In time of an economic crisis, the growth of unemployment acts together with a decrease in revenues from health insurance, therefore during these periods the costs of maintaining a healthcare system increase. At the same time, the WHO's warning is an important message for the national health systems, institutions, political decision makers:

"The healthcare system plays an important role in labour force protection. In case of economical crisis, people renounce private medical services, and rather turn to state financed medical services, although in most countries state financed health care is overburdened and underfinanced. The first goal to reach is that governments should maintain their state financed health care in time of economic crisis as well, and they have to take measures to protect vulnerable and poor social levels." [2].

Those Central European countries that suffer the most, received immediate financial help from International Monetary Fund. IMF credits control governments to spend more on healthcare, the population's health state is worse than in Western European countries; on the other hand, mass unemployment appeared in spring-summer 2009. Economical stimulating programs to liquidate the consequences of the crisis can go together with the development of health care and the boost of health care background industry. The condition of all of these can be that economic development programs should be able to integrate health development as well.

The effect of the economic world crisis on health and health care system can be positive and negative at the same time. As for the future, the interpretation of possible 
positive effects, a "best case scenario", should be considered as a research objective. The mechanisms are complex and complicated, but the following assumptions must be kept in mind.

The economic crisis may contribute to the valorization of health in several ways. In the cycle of economic prosperity people work more, the order of priority changes, and there is a tendency to take care less about one's health. During a crisis, if the unemployed takes the difficulties in a balanced way physically and psychically, health and health care becomes important because of the lack of fast lifestyle and the fast changing situations and in order to start work again. Crisis can result in reinforcing people's survival instinct. The effects of former world economical crises on health were examined, and it could not be clearly proven that the number of cardiac diseases and mortality caused by cirrhosis of the liver increased due to the world crisis and that more people were taken to psychiatric institute than usual. From the statistics it can be seen that $1 \%$ growth in the rate of unemployment during crisis decreased mortality rate by $0.5 \%$, which practically means that from hundred thousand people 5 people survived compared to usual periods [13].

The recent economic crisis with increased unemployment led to adverse economic and social implications in some countries of Central Europe including Hungary, too. After the economic downturn in these countries there were a lot of speculations about causes and effects, actions and reactions in the connection of economic recession and health. Most researchers agree that involuntary job loss increases the risk of psychiatric disorder and its somatic sequelae [14]. But in reality, is there a link between financial crisis and health? The social determinants of health are the circumstances of daily life-the conditions in which people are born, grow, live, work, and age-and the structural drivers of those conditions (unfair distribution of power, money, and resources). Both the conditions of daily life and the structural drivers will be influenced by the financial and economic crisis [15].

\section{The Hungarian Health Inequalities by Life Expectancy}

The marked deterioration in the health status of the Hungarian population has been going on since the middle of the 1960s. The general health status of the Hungarian people is worse than justified by the level of economic development. The adult mortality rate in Hungary is one of the worst among the European countries. Due to the very disadvantageous mortality rate of the middle-aged Hungarian males population [16] Hungary has a very bad situation in the European continent. "The mortality situation in Hungary, which had been worsening for decades, developed into an epidemiological crisis by the early 1990s, and it presently hits the whole adult population" [17]. On the other hand, the negative natural population growth rate, the very low birth rate, and the ageing population has also turned to a demographic crisis in Hungary at the beginning of the 1990s [18]. Hungary's economy has been experiencing significant transitional difficulties after 1990. Its social effects as the relevant problems of unemployment and poverty among low-income population groups have gone together with their "health recession." Jointly the role of the epidemiological, the demographic and the new economic crisis have shown some unique trends in the Hungarian health indicators over recent years.

Life expectancy in Hungary is among the lowest in Europe. From 1996 onwards there was a trend towards better life chances, but they are still a very long way from corresponding figures for wealthier Western European countries. Furthermore, large variations of life expectancy can be experienced in different parts of the country. The trend in life expectancy in Hungary has a similar pattern to most other Central and Eastern European countries and shows some characteristic features. The average life expectancy at birth was only 62 years in 1945, but as in all of the European states after the Second World War a downward trend in mortality rate was seen, which led to an increase period in life expectancy at birth [19]. This favourable tendency was caused by the decreased number of maternal, neonatal and infant mortality, because of the developement of the preventive strategies and implements for the infectious diseases since the beginning of the 20th century in Europe.

The average life expectancy at birth and its changes continuously depended on the improvement or the worsening of the mortality situation in Hungary in the second half of the 20th century. The remarkable improving was mainly experienced until the beginning of the 1970s. Naturally, the result of this positive trend was the advantageous life chances among Hungarian middle-aged population. However, the substantial improvement was followed by a marked deterioration of life expectancy at the end of the 1970s, because from 1966 the main health indicators changed for the worse. The deterioration of the Hungarian life expectancy reached its bottom in 1985, but this could not be followed by a period of upswing due to the change of regime and the socioeconomic transformation (Figure 4). Nevertheless, the role of the transition caused another bottom in 1993. In this year the life expectancy fell to unprecedented levels: for men 64.5 and for women 73.8 years (69.2 years both sexes combined). The fall in life expectancy in 1989-1993 has been largely due to a sharp rise in premature mortality of the middle-aged male's population. The moderation of mortality rate after 1993 resulted in that the life chances could increase again over 70 years from the second half of the 1990s. Thus, it could increase over 71 years from 2000, over 72 years from 2002, and over 73 years from 2006.

Now the average number of it is 74.0 years, for males is 70.1 years and for females is 77.9 years in Hungary (2009). According to the latest available data, the average life expectancy at birth in Hungary remains among the lowest in European Union (Figure 2).

Life expectancy in Hungary shows characteristic regional variations (Figure 3), a feature which is also typical of other indicators of health status. Life expectancy in Hungary has been increasing recently but in a geographically uneven distribution [20]. Broadly speaking, the life chances in the 


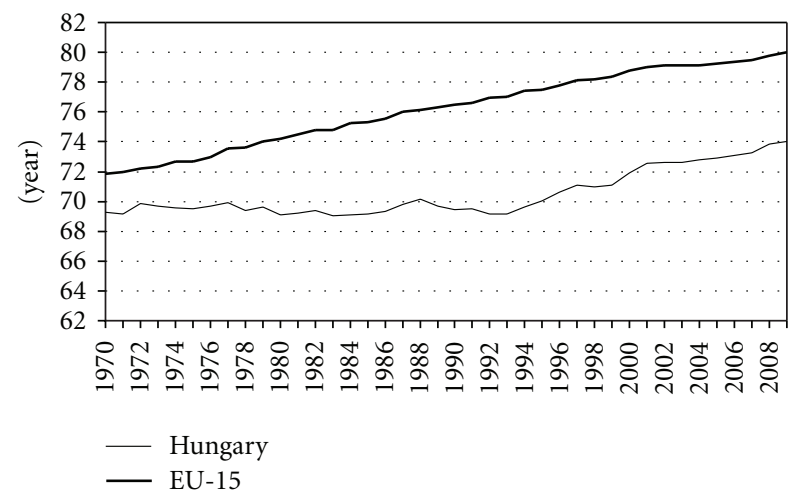

Figure 2: The average life expectancy at birth in Hungary and in EU-15, 1970-2009. Data source: http://www.euro.who.int/hfadb/.

Eastern part of the country are a great deal worse than that of the population in the Western part of Hungary. The difference between the average life expectancy of the counties of the best and the worst values is more than 2.5 years [21]. The life chances and its regional differences within Hungary are influenced by the socioeconomic situation of the counties. The relative position to each other has not or hardly changed in the past 15 years. The most advantaged and the worst disadvantaged counties were the same at the beginning of the 1990s and nowadays, too. The mortality trends have remained disadvantageous for North Eastern Hungarian counties (Borsod-Abaúj-Zemplén, Szabolcs-Szatmár-Bereg) and for Southern Transdanubian counties (especially Somogy county). Unemployment in Hungary mainly affects these regions. Of those who are unemployed now in Hungary, 45 percent live in these undeveloped rural regions in the Eastern and South Western part of the country [22].

One of the most interesting things about the widening health gap between the Eastern and the Western halves of Hungary is that it had already begun to evolve during the 1970 s and 1980s, but also has suggested the common origins of the health trends and the uprisings of 1989. Considering the significant mortality and life chances data, it is impossible to disregard the fact that in the Eastern part of Hungary the number of people in multiply disadvantaged position is very high, thus struggling with many economic (e.g., unemployment) and social problems (e.g., ethnical minority groups). In the Eastern half of Hungary the percentage people belonging to the upper strata of the social hierarchy is mostly low.

\section{Unemployment and Life Expectancy in Hungary after 1990}

The scale of the health differences within Hungary is surprising. The following regional analysis finds a middle-strong relationship between unemployment and life expectancy. These health differences structure is not confined to differences between the poor and the rest of society, but instead run right across society with every level in the social hierarchy having worse health than the one above it. This is the main point that health differences have typical pattern due to the socioeconomic spatial position of the Hungarian counties. I also found out what I expected, which is that huge gaps in health exist between Eastern and Western counties according to the regional inequality of Hungary. With the development of capitalism after 1990, the economic and social differences among the regions of Hungary increased. Economic deterioration has become especially intensive in Eastern and rural Hungary [23].

The disadvantaged life expectancy in Hungary presently hits the whole adult population, but its spatial inequalities are influenced by the connection between life expectancy and economic development.

The early 1990s labour market in Hungary was characterized by the rapid decline of employment and the fast rise of unemployment. Unemployment rate reached its peak in $1993(12.1 \%)$ together with the highest mortality rate $(14.6 \%)$ and the shortest life expectancy (69.2 year) (Figures 4 and 5). Improvement in unemployment started from the middle of the 90 s in Hungary, due to which unemployment decreased continually until 2004. During the 15 years following the Second World War life expectancy at birth grew spectacularly in Hungary, and for 30 years - while in the European Union there was a constant rise-it has not changed. Nowadays Hungarians can expect to live four and a half years longer than in the period of the economic regime. The growth of life span was the smallest in Northern Hungary after 1996.

Compared to the early 90s, the root cause of unemployment changed in the present crisis. As a consequence of the changement of regime, employment in agriculture and industry became restricted, but from the end of the 90s, the proportion of unemployed higher education graduates has increased. "The lowly qualified were the losers of the transition not only in terms of labour market and life circumstances, but in life chances as well" [24]. The present crisis has significantly affected highly qualified labour force, the employees of tertiary and quaternary sector. Thus in the last decade the social groups with favourable health index and better life expectancies appeared as unemployed. According to a more optimistic forecast, this is the reason why growth of life expectancy at birth will stagnate in Hungary as a result of the crisis, but it will not decrease. However, it could also cause some problems in the future as life expectancy in Hungary is some 6-7 years behind the Western European average.

Based on a correlational matrix (Table 1) we can have an overview of the connection between health and economic factors of the middle-aged population. GDP per capita for middle-aged males shows the closest connection with health and life expectancy. Employment rate shows the closest in connection with health, but it is significant for men. Thus employment determines men's "healthy" life expectations more.

It is justified by the fact that men's healthy life expectancy is in close connection with the unemployment rate. From the examined economic factors, unemployment rate determines the most significantly life chances, mainly for middle-aged males, as $60 \%$ of unemployed in Hungary are men. 


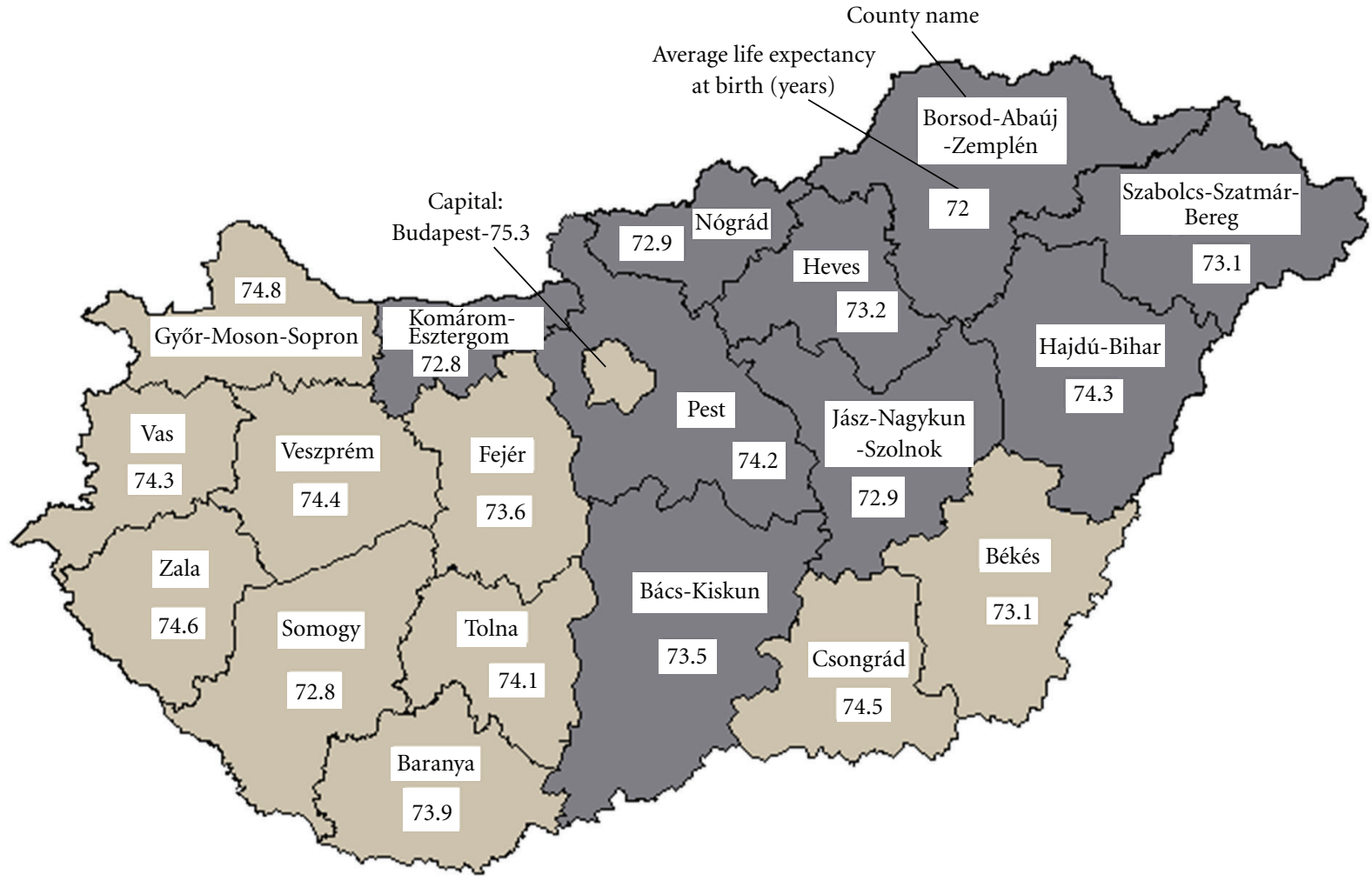

Unemployment (\%)

Above average (9)

Below average (11)

Average: $12.6 \%$

Figure 3: The unemployment rate (\%) and the average life expectancy at birth (years) in the Hungarian counties, 2009. Data source: http://portal.ksh.hu/ and Hungarian County Statistical Yearbook, 2009.

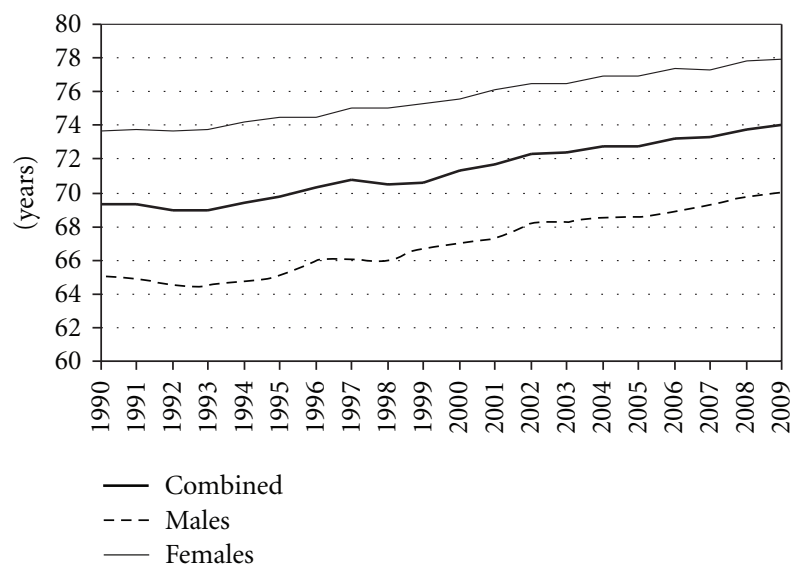

Figure 4: The average life expectancy at birth by sex, 1990-2009. Data source: Hungarian Demographic Yearbook 1949-2009.

In the connection between average life expectancy at birth and economic development, GDP per capita, average income, and unemployment rate are equally determinative [16]. The correlation coefficient measuring the strength of the link between unemployment rate in counties and

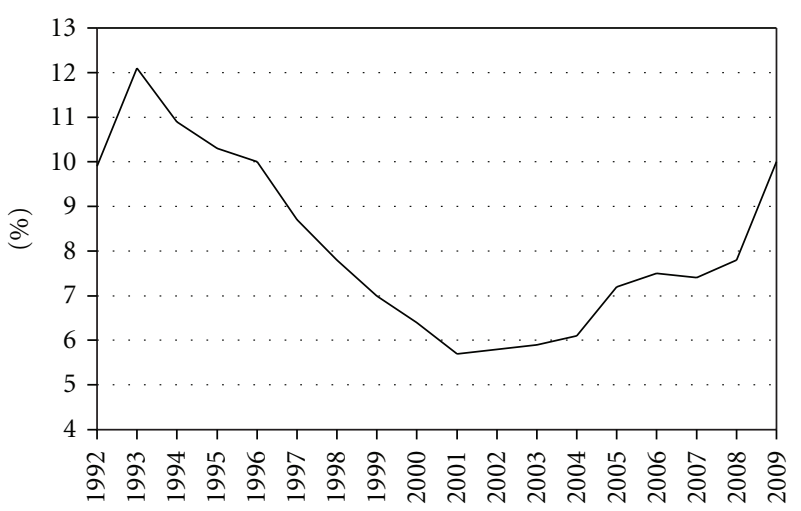

FIGURE 5: Unemployment rate, 1992-2009. Data source: Hungarian Demographic Yearbook 1992-2009.

life chances was 0.77 in 1993, 0.63 in 2007, and 0.69 in 2009.

It is not true for the whole country that higher unemployment goes together with lower life expectancy (Figure 6). The situation is the worst in Borsod-Abaúj-Zemplén county, 
TABLE 1: Connection between health and economic factors by Pearson's correlation coefficient $\left(R^{2}\right), 2009$.

\begin{tabular}{lccc}
\hline Health factors & $\begin{array}{c}\text { GDP per capita } \\
\text { (thousand forint) }\end{array}$ & $\begin{array}{c}\text { Economic factors } \\
\text { Full employment rate } \\
(\%)\end{array}$ & Unemployment rate (\%) \\
\hline $\begin{array}{l}\text { Healthy life expectancy at age of 45, } \\
\text { males (year) }\end{array}$ & 0.65 & 0.81 & -0.84 \\
$\begin{array}{l}\text { Healthy life expectancy at age of 45, } \\
\text { females (year) }\end{array}$ & 0.50 & 0.63 & -0.67 \\
\hline
\end{tabular}

Data source: http://portal.ksh.hu/.

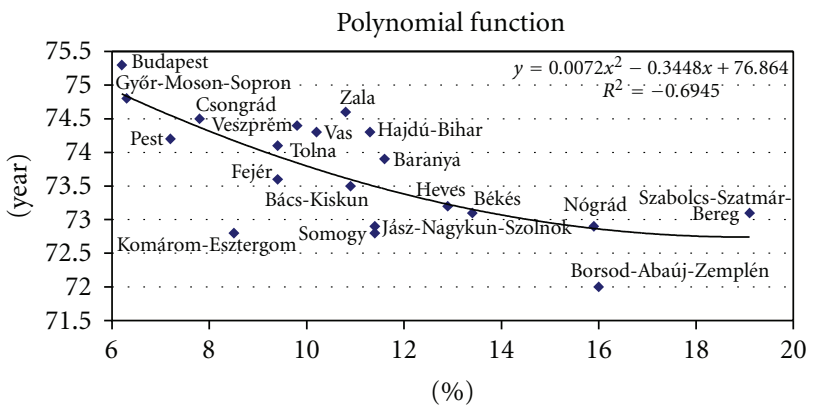

FIGURE 6: Correlation between unemployment rate (\%) and average life expectancy at birth (year) by county level, 2009. Data source: Hungarian Regional Statistical Yearbook, 2009.

where unemployment was high before the crisis, and it increased even more in 2009, and life chance amelioration was the lowest in the country after 1996. In Györ-SopronMoson and Vas county life chances are less favourable than they would be expected according to the unemployment rate. Most probably unemployment is less significant when considering the average life expectancy due to the fact that Budapest is extremely well developed.

If we adjust the axes of the dot diagram to the two indicators' average values (unemployment 12.6\%; life expectancy 73.7 years in 2009), we can identify the counties with the best and worst life chances (Figure 7). The western and central part of the country stands out unequivocally, where favourable social-economic environment results in better life chances. In East and North East Hungary the unemployment exceeding that of the Hungarian average is linked to the worst life expectancy. Compared to the situation before the crisis, Pest county remarkably lost its position, where high unemployment resulted in that it derives from polynomial curve's trend line in the most negative extent.

Based on county data, in the 90 s, regarding the main causes of death, unemployment showed significant correlation with standardized deaths of adult population aged between 15 and 59 caused by cardiovascular diseases $\left(R^{2}=\right.$ $0.68 ; 1994-1998$ average). In that period, the development of cardiovascular diseases not only developed because of the low incomes caused by unemployment and its consequences (e.g., limited possibilities to healthy life) but the psychic experience of being redundant and the depression caused by it were also risk factors [25]. From the group of car-

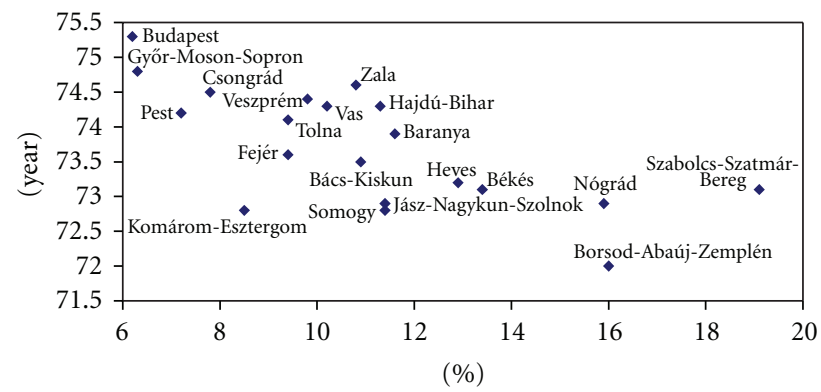

FIgure 7: The relative position of Hungarian counties by the connection between unemployment rate (\%) and average life expectancy at birth (year), 2009. Data source: Hungarian Regional Statistical Yearbook, 2009.

diovascular diseases, the cerebral diseases, and death caused by brain haemorrhage showed a similarly strong correlation with unemployment. The situation was the least favourable in Borsod-Abaúj-Zemplén, Szabolcs-Szatmár-Bereg, and Nógrád counties, where beside the high rate of unemployment, the mortality rate was also the highest in the country.

The suicide rate in Hungary has shown a steady decline from 45.9 per 100,000 in 1984 to 31.7 in 1997, a fall of more than 30\%. This decline was greater after 1990 when the rate was 39.9 per 100,000 and when the political and economic changes in Eastern Europe began [26]. Unfortunately, Hungary still carries high suicide rate and has not moved away from ranking fifth in the world in suicide rates over the past five years. In Hungary since 1990, there have been significant increases in unemployment and poverty. The suicide in Hungary is associated with possible risk factors such as unemployment and socioeconomic decline [27]. Among those people who commit suicide the rate of unemployment is app. 9\%-10\%. The correlation between suicide and unemployment rate is 0.4657 (2008). The most unfavourable region in Hungary by suicide is Southern Great Plain (Figure 8).

The average income of an active population living on a given area is in correlation with health state. Those with higher income can spend more on health conscious life, have more possibility to healthy lifestyle, and have a more favourable access to-for example, private-health care. There was a typical correlation in the 90s between monthly average income and the life expectancy of men at the age of $45\left(R^{2}=0.478 ; 1994-1998\right.$ average $)$. 


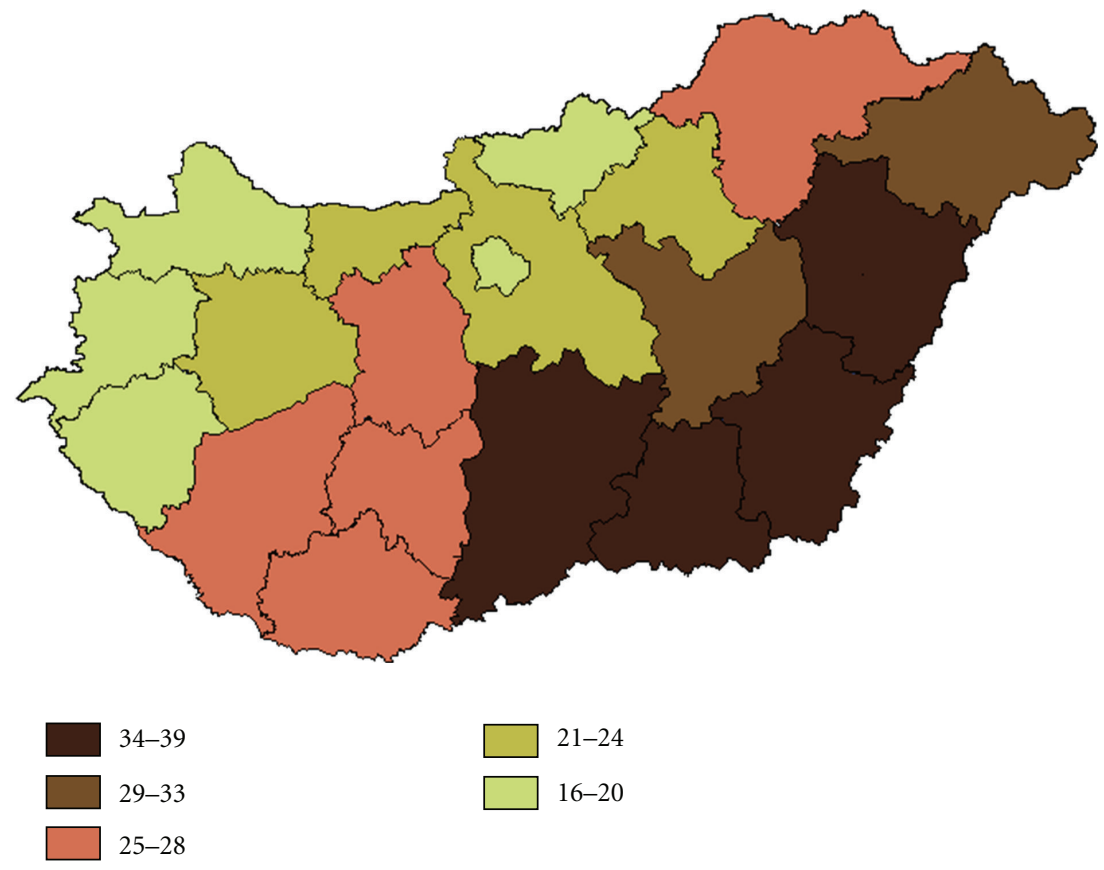

Figure 8: Suicide rate per 100,000 in the average of 2003-2008. Data source: Hungarian Medical Statistical Yearbook, 2008.

\section{Conclusion}

The health status of the Hungarian population has been extremely unfavourable for many years. Regarding certain diseases and causes of death, Hungary is in a negatively outstanding position in international statistics. Hungary has one of the lowest life expectancy rates at birth among the member states of the European Union (Chenet et al. [28]). The poor ranking of Hungary on the list of life expectancy at birth in the European Union (EU-27) has not changed during the last 35 years, but the size of deviation-expressed in years-from other countries has changed substantially (Balogh et al. [29]). The low life expectancy is mainly due to high mortality rate from cardiovascular diseases. In the morbidity pattern, the diseases of the circulatory system have very high share. Hypertension is almost an endemic disease in Hungary, and ischemic heart disease is the dominant factor of mortality in Hungary.

The "Western-Eastern gradient" of the Hungarian economic environment can influence the spatial structure of life expectancy. The concept of socioeconomic health differences refers to the systematic differences in health between people with different positions in the social stratification. Important is that these differences in health are not confined to differences between the highest and the lowest social classes [30]. Health follows a social gradient: the higher the position in the social hierarchy, the lower the risk of ill health and premature death (Marmot and Wilkinson [31]). Over the past decades, evidence of a social gradient in life expectancy has accumulated in Hungary. This widening relative gap is mostly due to a faster decline in mortality among people of higher socioeconomic status than the decline among those of lower socioeconomic status.

\section{Acknowledgment}

This paper was supported by the János Bolyai Research Scholarship of the Hungarian Academy of Sciences.

\section{References}

[1] M. Lalonde, A New Perspective on the Health of Canadians. A Working Document, Government of Canada, Ottawa, Canada, 1974.

[2] World Health Organization, "Health systems financing: the path to universal coverage," World Health Report, 2010, WHO, Geneva, Switzerland, http://www.who.int/whr/2010/ en/index.html.

[3] M. G. Marmot and R. Wilkinson, Eds., The Social Determinants of Health, Oxford University Press, Oxford, UK, 2003.

[4] R. Wilkinson and K. Pickett, The Spirit Level —Why Equality is Better for Everyone, Penguin Books, London, UK, 2010.

[5] J. Benach, C. Muntaner, and V. Santana, Employment Conditions and Health Inequalities, WHO-CSDH, Montreal, Canada, 2008.

[6] D. Dooley, J. Fielding, and L. Levi, "Health and unemployment," Annual Review of Public Health, vol. 17, pp. 449-465, 1996.

[7] U. Hegerl, M. Wittmann, E. Arensman et al., "The 'European Alliance Against Depression (EAAD)': A multifaceted, community-based action programme against depression and suicidality," World Journal of Biological Psychiatry, vol. 9, no. 1, pp. 51-58, 2008.

[8] Y. H. Noh, "Does unemployment increase suicide rates? The OECD panel evidence," Journal of Economic Psychology, vol. 30, no. 4, pp. 575-582, 2009.

[9] L. Gilson and H. Schneider, "Understanding health service access: concepts and experience," in Global Forum Update on Research for Health, vol. 4, pp. 28-32, 2008. 
[10] C. Pope and N. Mays, "Reaching the parts other methods cannot reach: an introduction to qualitative methods in health and health services research," British Medical Journal, vol. 311, no. 6996, pp. 42-45, 1995.

[11] D. Raphael, "Interactions with the health and service sector," in Poverty and Policy in Canada: Implications for Health and Quality of Life, D. Raphael, Ed., pp. 173-203, Canadian Scholars' Press, Toronto, Canada, 2007.

[12] J. Mackenbach and M. Bakker, Eds., Reducing Inequalities in Health: An European Perspective, Routledge, London, UK, 2002.

[13] M. Suhrcke, M. Mckee, R. Sauto Arce, S. Tsolova, and J. Mortensen, The Contribution of Health to the Economy in the European Union, Europen Commission, Health \& Consumer Protection Directorate-General, Luxembourg, 2005.

[14] R. Catalano, "Health, medical care, and economic crisis," New England Journal of Medicine, vol. 360, no. 8, pp. 749-751, 2009.

[15] M. G. Marmot and R. Bell, "How will the financial crisis affect health?” British Medical Journal, vol. 338, pp. 1314-1321, 2009.

[16] P. Józan, "Some features of mortality in Hungary between 1980 and 1994," in Atlantic Studies on Societies in Change, vol. 85, pp. 111-138, 1998.

[17] P. Jozan, “The epidemiological future," Health Policy, vol. 19, no. 1, pp. 19-32, 1991.

[18] L. Hablicsek, "Demographic situation and population policies in Hungary," in New Demographic Faces of Europe, T. Kučera, Ed., pp. 163-182, Springer, Berlin, Germany, 2000.

[19] J. T. Kowaleski and W. Starzynska, "Demographic impacts in Central and Eastern European countries," International Advances in Economic Research, vol. 2, pp. 334-340, 1996.

[20] A. Uzzoli and D. Szilágyi, "Life expectancy and its regional inequalities in Hungary," in Geographica Pannonica 2009/4, pp. 127-136, 2009.

[21] A. Uzzoli, "The mortality situation and its spatial dimension in Hungary," in Czech Regional Studies 2008/2, pp. 41-50, 2008.

[22] Gy. Enyedi, Public Participation in Socially Sustainable Urban Development, UNESCO, Centre for Regional Studies, Pécs, Hungary, 2004.

[23] J. Szalai, "Some aspects of the changing situation of women in Hungary," Journal of Women in Culture and Society, vol. 15, pp. 152-170, 1991.

[24] K. Kovács, "The mortality and health status of wome," in Changing Roles, I. Nagy, M. Pongrácz, and I. G. Tóth, Eds., pp. 163-174, Tárki Social Research Institute, Budapest, 2006.

[25] Z. Szvitecz, Quality of Life and Health, Hungarian Central Statistical Office, Budapest, Hungary, 2002.

[26] Z. Rihmer, L. Appleby, A. Rihmer, and N. Belso, "Decreasing suicide in Hungary," British Journal of Psychiatry, vol. 177, p. 84, 2000.

[27] K. Almasi, N. Belso, N. Kapur et al., "Risk factors for suicide in Hungary: a case-control study," BMC Psychiatry, vol. 9, article 45, 2009.

[28] L. Chenet, M. McKee, N. Fülöp et al., "Changing life expectancy in Central Europe: is there a single reason?" Journal of Public Health Medicine, vol. 18, pp. 329-336, 1996.

[29] S. Balogh, R. Papp, P. Józan, and A. Császár, "Continued improvement of cardiovascular mortality in Hungary - impact of increased cardio-metabolic prescriptions," BMC Public Health, vol. 10, no. 422, pp. 1186-1196, 2010.
[30] S. Willems, The socio-economic gradient in health: a never ending story?, Ph.D. thesis, Ghent, Belgium, 2005, A descriptive and explorative study in Belgium, Department of Family Medicine and Primary Health Care, Ghent University.

[31] M. G. Marmot and R. Wilkinson, Eds., The Social Determinants of Health, Oxford University Press, Oxford, UK, 2003. 


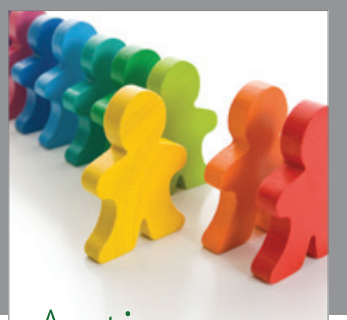

Autism

Research and Treatment
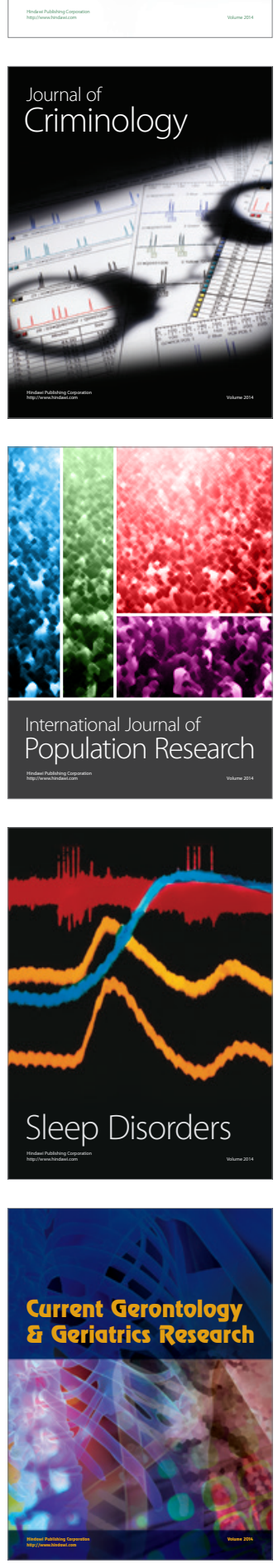
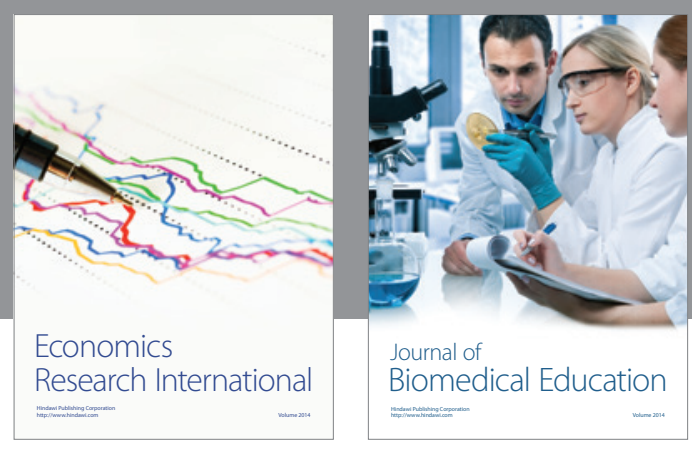

Journal of

Biomedical Education

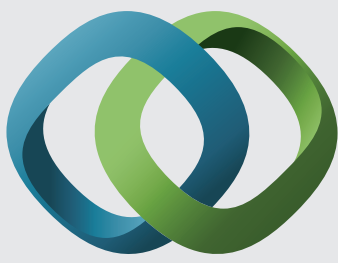

\section{Hindawi}

Submit your manuscripts at

http://www.hindawi.com
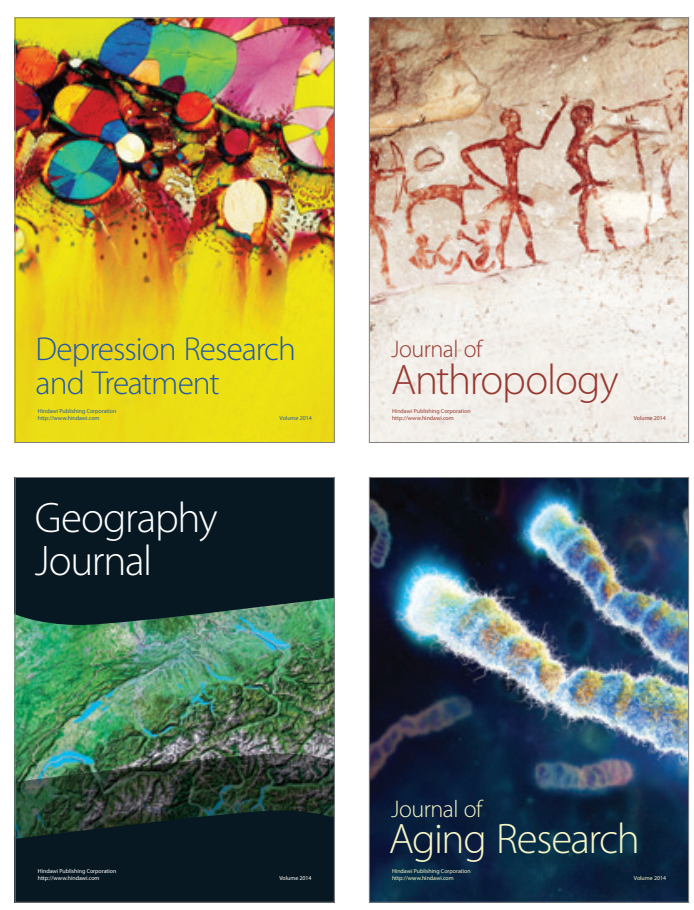

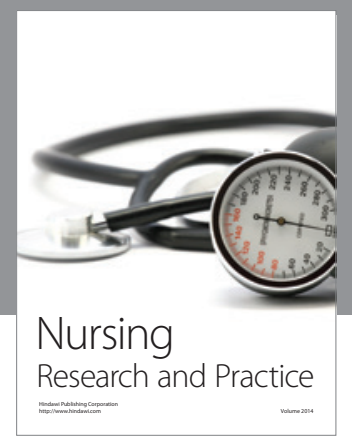

Nursing

Research and Practice

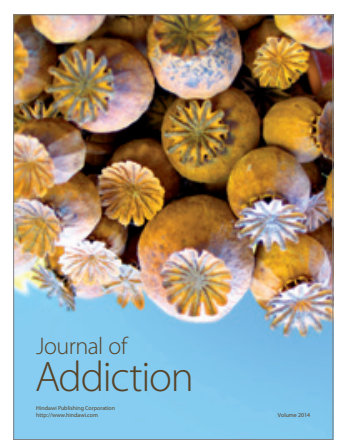

Child Development

Research

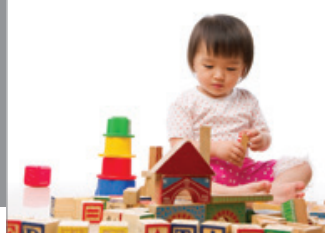

迥
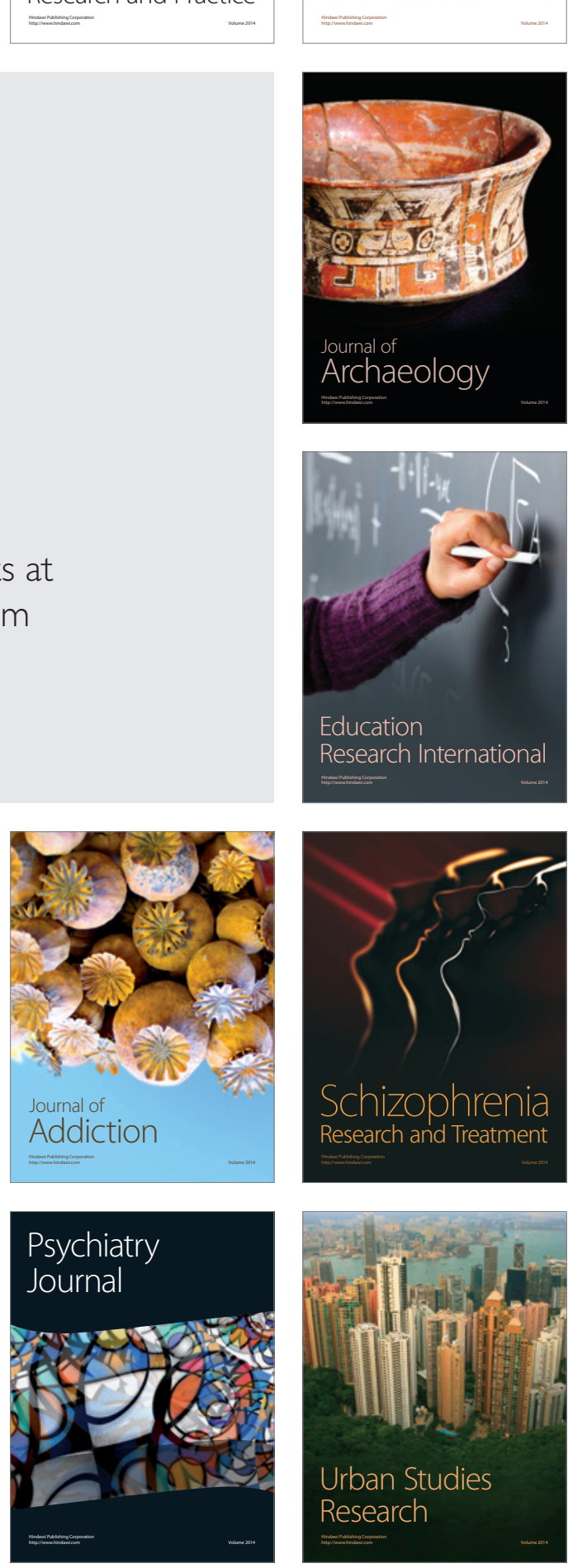